\title{
Technostress Analysis in Educational Institutions during the COVID-19 Confinement
}

\author{
Franco Arturo Urbano O. ${ }^{1}$, Gabriel Elías Chanchí G. ${ }^{2}$, Wilmar Yesid Campo M. ${ }^{3}$ \\ ${ }^{1}$ Fundación Universitaria de Popayán, Calle 5 No. 8-58, Popayán, Colombia \\ ${ }^{2}$ Universidad de Cartagena, Av. del Consulado, Calle 30 No. 39B-192, Cartagena, Colombia \\ ${ }^{3}$ Universidad del Quindío, Cra. 15 Cll. 12 norte, Armenia, Colombia
}

\begin{abstract}
The COVID-19 pandemic has forced organizations to adapt their different processes to the dynamics of virtuality. Thus, in the specific case of the educational context, the remote presence methodology has been implemented with the support of the advantages provided by Information and Communication Technologies (ICTs). Despite the fact that ICTs dynamise the different processes of organizations, it has been shown that they can affect the stress of company workers. This paper presents the development of a technostress analysis study applied to the educational context, taking as a case study an educational institution from Popayán-Colombia.
\end{abstract}

Keywords - COVID-19, ICT, technostress, remote presence, work stress.

\section{Introduction}

The pandemic caused by COVID-19 has forced organizations from different sectors such as health, industry, education, among others, to adapt their different processes to the dynamics of virtuality

DOI: $10.18421 /$ TEM104-22

https://doi.org/10.18421/TEM104-22

Corresponding author: Gabriel Elías Chanchí G., Universidad de Cartagena, Av. del Consulado, Calle 30 No. 39B-192, Cartagena, Colombia

Email: gchanchig@unicartagena.edu.co

Received: 13 July 2021.

Revised: 07 October 2021.

Accepted: 12 October 2021.

Published: 26 November 2021.

(c) BY-NC-ND (c) 2021 Franco Arturo Urbano O., Gabriel Elías Chanchí G. \& Wilmar Yesid Campo M.; published by UIKTEN. This work is licensed under the Creative Commons Attribution-NonCommercial-NoDerivs 4.0 License.

The article is published with Open Access at www.temjournal.com capitalizing on the advantages provided by the Information and Communications Technologies (ICT) [1], [2], [3].

In this way, during the COVID-19 pandemic at the educational context, different challenges related to the technological gap had to be addressed, and several processes had to be adapted to the remote presence methodology (meetings, academic meetings, and methods of evaluation and monitoring) [4],[5],[6]. In this sense, the dissemination and adoption of ICTs during confinement was a key aspect for the development of work activities.

Although ICTs generate different benefits in organizations such as the reduction of operating costs, labour optimization, and process efficiency [7], different investigations show that they are a "doubleedged sword", which has a double face or a dark side [8], [9]. On the one hand, they add value to operational activities; and on the other, they can generate stress in workers, better known as technostress, with consequences for health and wellbeing [10].

According to [11], technostress can be defined as: "a negative psychological state related to the use of ICTs or the threat of its use in the future. This state is conditioned by the perception of a mismatch between the demands and related resources with the use of ICTs that leads to a high level of unpleasant psychophysiological activation and the development of negative attitudes towards ICTs". Likewise, according to [12], technostress can be understood as the negative impact on the attitudes, thoughts, behaviours, or body physiology caused directly or indirectly by technology. On the other hand, at the medical level, technostress can be defined as an adaptive disease caused by the lack of ability to deal with new computer technologies in a healthy way [13]. In the same way, in [14], technostress is not considered a disease but a negative impact in the cognitive, emotional, physiological, attitudinal, and behavioural levels caused directly or indirectly by technology. 
At the level of technostress, [15] highlights the cognitive, physiological, behavioural, and organizational consequences. In the first one, anxiety, irritability, concentration, and memory difficulties, among others are seen. In the physiological one, consequences such as muscle pain, sleep disorder, eye fatigue, among others are evidenced. In the behavioural one, consequences such as nervous movements, frequent blinking, and talking to the computer are noticed. In the organizational one, consequences such as reduced performance and loss of quality are the most notorious.

This paper presents the results of the adaptation and application of a technostress measurement instrument in an educational context during the COVID-19 pandemic. It was developed as a case study in an educational institution from the urban area of Popayán, Cauca, Colombia. This institution is a public school, and it is classified as one of the best Colombian educational institutions that always ranks among the best 3 in the department of Cauca, making it a benchmark for others. By applying the instrument, the idea is to show how in the face of confinement and the move towards work-at-home strategies, institutions are forced to adapt their academic and administrative processes, generating stress levels in their workers that ultimately affect the results students obtain on national tests, which measure academic performance. In this sense, this article aims to serve as a reference point regarding the extrapolation of these types of studies in other organizations that help taking measures to mitigate technostress.

The rest of the paper comprises 4 other sections as follows: Section 2 presents a set of related works that were considered for the development of this research. Section 3 presents the different methodological phases that were considered for the present investigation. In section 4, the application of an instrument for the evaluation of technostress in teachers, managers, and administrators is presented as a result. Finally, section 5 presents the conclusions and future work derived from this research.

\section{Related Works}

This section presents a set of related work that was considered for the development of this research.

In [12], a systematic review of the literature was carried out on different contributions related to the subject of technostress within the Web of Science database. The study developed by the authors sought to identify the factors associated with ICTs that generate technostress in workers. In this sense, there were several stressors that appeared in the literature such as: information overload, quantity and content of interruptions associated with ICTs, pressure to be constantly available, imbalance between external demands and internal capacities, work overload and role ambiguity, technological dependence, and lack of training. Likewise, within the inhibitors of technostress, the following stand out: digital literacy, support and assistance, participation, maturity of the organizational culture in terms of work/personal life separation, among others.

In [13], a literary review on technostress addressed its conceptualization, its psychological and physiological symptoms, as well as its possible consequences (psychosocial damage, psychosomatic complaints, fatigue, boredom, cynicism, anxiety, among others). In the same way, the article allowed to conclude that technostress is present especially in managerial jobs, but it also affects other work environments, especially those subject to constant changes and updates. It was also concluded that there are still no standardized and unified models for its evaluation, so it is imprecise to classify it as a psychosocial risk factor; however, it should be considered as another factor for work stress.

In [14], the authors presented a literary review on the evolution of the concept of technostress and its consequences, as well as the possible characteristics or factors that have an influence in its origination on individuals. Thus, analysing the consequences derived from technostress, the authors identified: overexposure to a large amount of data and information, work overload and flexibility caused by the use of ICTs, job satisfaction, decreased organizational commitment, reduced performance, and ambiguity in the role of the worker.

In [16], the study was developed to identify the incidence of the use of social networks by company workers regarding the building of technostress and its possible influence on the performance of workers. For the development of the study, an evaluation instrument was generated that was completed by 415 workers from different areas and companies. The study concluded that technostress derived from the use of social networks has a negative influence on worker performance and a negative impact when the tasks performed do not have autonomy and are not varied.

In [17], the study sought to identify technostress in workers who use mobile applications at work, as well as the factors that affect it and the possible alternatives to mitigate it. In this sense, an instrument was applied to 210 workers of a company, managing to determine the possible inducers of work exhaustion: overload, invasion, tool complexity; while possible inhibitors that stand out are literacy, technical support, among others.

In [18] a perception analysis study is presented regarding the development of academic activities 
during confinement by Systems Engineering students at the University of Cartagena. For the analysis of perception, the sentiment analysis technique was used, which allowed to determine the polarity level (positive, negative, neutral) of the different opinions expressed by the students regarding the difficulties and advantages of the remote presence methodology. As a result, $27.47 \%$ of negative polarity was obtained while the positive polarity was $25.47 \%$. In the same way, regarding the advantages evidenced, it was observed that the positive polarity was $33.24 \%$ and the negative polarity was $17.73 \%$. In this sense, the study concluded that systems engineering students, despite the adaptation process, have a positive perception of academic processes and look optimistically at the possibility of improving the practices developed in the remote presence methodology.

In [19], an analysis on the resistance of Italians to comply with biosafety and self-care measures during the confinement caused by COVID-19 is presented. The authors concluded that a possible explanation for such behaviour is psychological reactance, which is defined as the unpleasant sensation that human beings have when they perceive someone or something that threatens their behaviour freedom. Finally, the authors propose as a possible solution to this resistance, the application of reverse psychology, as well as the use of communication free from authoritarian messages by government entities.

In [20], a study that analysed how health, social, and psychological factors are related to resilience during the pandemic in the Spanish population was done. Based on this, a questionnaire with 43 closed questions in an online format was applied to a sample of 3,436 people residing in Spain during the second extension of the state of alarm for COVID-19. The results obtained showed positive associations between resilience and presenting symptoms of COVID-19 (mainly in men), as well as having suffered deaths in their surroundings. In the same way, the research concluded that having a disease diagnosed prior to COVID-19 has a negative effect on resilience since the values obtained in the surveyed population are lower than in the population without previous diseases.

In [21] a study whose objective was understanding the behaviour of the variables: higher education, research, and digital technologies during the pandemic caused by COVID-19 was carried out. This study was developed using infometric techniques regarding web content in 25 Latin American universities that were selected considering the QS Latin America Ranking index and the number of infections by COVID-19. The results allowed to determine that the information about the academic programs is accessed through digital environments.
Likewise, in terms of research, a low projection of progress in times of pandemic prevails, generating uncertainty regarding the dynamization of the science-technology-humanities trilogy in Latin America. Likewise, the scope of technologies for overcoming student dropouts is weakly diffused. On the other hand, the visibility of strategies that guarantee continuity is omitted, generating paralysis or delays in the development of scientific and technological advances.

In [22] the authors evaluated a set of strategies and pedagogical and technological resources used by Argentinian teachers within the virtual education model implemented during the preventive confinement and closure of educational establishments arranged before the emergency caused by COVID- 19. The study applied a quantitative instrument on a total of 777 individuals, mostly teachers, from different institutions in Mendoza-Argentina. The study made it possible to show the existing inequalities in the use of digital pedagogical technologies and resources. These differences are manifested in relation to the type of management, the educational level, the socioeconomic situation of students, the academic performance, and the support from the students' family.

\section{Methodology}

This section presents the description of the different phases of the methodology considered in this article. Thus, the methodology comprises 4 phases: the conceptualization of technostress, the design of the evaluation instrument, the application of the instrument, and the analysis of the results (see Figure 1.).

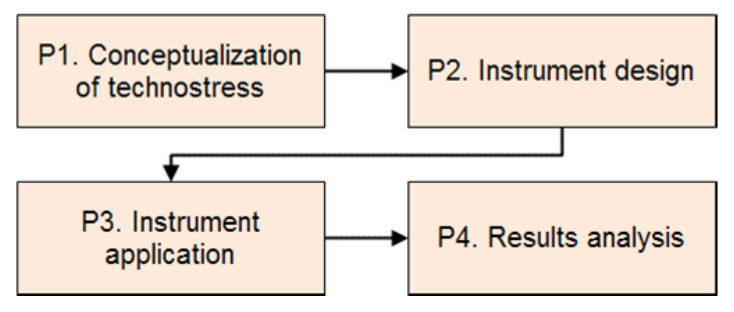

Figure 1. Methodology phases

In phase 1, the concept of technostress was characterized from the literature, as well as its influence on institution workers. In phase 2 , an adaptation of the technostress analysis instrument defined in [23] was carried out based on the characterization made in phase 1 . The adapted instrument had 2 sections, the first one collected the data associated with the profile of the teachers, managers, and administrators evaluated while the second one was in charge of evaluating aspects classified in three dimensions: affective (anxiety vs. 
fatigue), attitudinal (sceptical attitude towards technology), and cognitive (ineffectiveness beliefs in the use of technology). All these aspects referred to the use of information technologies in the development of academic activities during confinement by the teachers evaluated [23]. In this sense, the 4 key factors considered in the evaluation corresponding to the 3 dimensions mentioned were anxiety, fatigue, scepticism, and ineffectiveness.

Table 1. shows the questions considered in the technostress assessment instrument, which includes a total of 20 questions (4 for section I and 16 for section II). In phase 3, the evaluation instrument adapted to 46 teachers from the Nuestra Señora del Carmen Educational Institution was applied, using the tools provided by Google Forms. Finally, in phase 4 , the analysis of the results obtained using descriptive statistics was done.

Table 1. Assessment instrument designed

\begin{tabular}{||l}
\hline Section \\
Q1. What is your position within the \\
institution? (Teacher, principal, or \\
administrative) \\
Q2. What is your gender? \\
Q3. What is your age? \\
Q4. Where do you work on? \\
(Preschool, elementary, high school) \\
The questions in this section were \\
posed to be answered on a scale from \\
1 to 6. \\
Q5. Over time, have you noticed if \\
you are interested in technological \\
tools? \\
Q6. Do you feel less and less affinity \\
with the use of new technologies? \\
Q7. Are you indifferent to the \\
contribution of ICTs to your work? \\
Q8. Have you doubted about the \\
meaning of work when using ICTs? \\
Q9. Do you find it difficult to relax \\
after a workday using ICTs? \\
Q10. Do you feel exhausted after you \\
finish working with new technology? \\
Q11. Are you so tired when you finish \\
working with it that you cannot do \\
anything else? \\
Q12. Is it difficult for you to focus on \\
something else after working with \\
ICTs? \\
Q13. Do you feel tension when \\
working with ICTs? \\
Q14. Are you scared of thinking that \\
you can destroy a large amount of \\
information by improper use? \\
Q15. Are you hesitant of using \\
technology for fear of making \\
Section \\
Q16. Does working with ICTs make \\
\hline
\end{tabular}

you feel uncomfortable, irritable, and impatient?

Q17. In your opinion, do you get the results you expect when using ICTs? Q18. Is it difficult to work with information and communication technologies?

Q19. Do people tell you that you are ineffective using ICTs?

Q20. Are you insecure about finishing your tasks well when using new technologies?

\section{Results}

This section presents some data that characterize the members of Nuestra Señora del Carmen Educational Institution who participated using the defined instrument. The instrument was filled out by 46 people; $91.3 \%$ correspond to personnel dedicated exclusively to teaching tasks and the rest to performing administrative tasks. Likewise, 78.3\% correspond to women who work in the institution.

Figure 2. shows the percentage distribution of participants by age ranges: between 20 to 30 years old, 31 to 40,41 to 50,51 to 60 , and 61 and older.

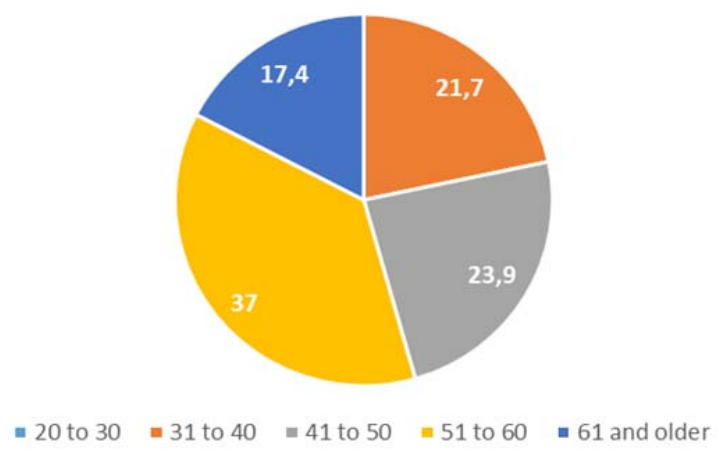

Figure 2. Participants' age range

According to [23] technostress as psychosocial damage is measured with three types of dimensions: affective (anxiety vs. fatigue), attitudinal (sceptical attitude towards technology), and cognitive (beliefs of ineffectiveness in the use of technology). The items on these scales were answered by workers who use ICTs in their work environment using a Likerttype frequency scale that ranges from "0" (nothing / never) to "6" (always / every day). Thus, high scores in these dimensions are indicators of technostress in its two manifestations: techno-anxiety (high scores in anxiety, scepticism, and ineffectiveness) and technofatigue (high scores in fatigue, scepticism and ineffectiveness.

The strategy for obtaining the scores for each scale (fatigue, anxiety, scepticism, and ineffectiveness) consists of adding the scores obtained on each item that belong to each scale and dividing the result by 
the number of items on the scale (the four scales are made up of four items each). The same procedure must be followed to obtain the score on each of the remaining dimensions for each worker. Thus, Figure 3. shows the values obtained for the 4 variables associated with technostress of members who work in the educational institution.

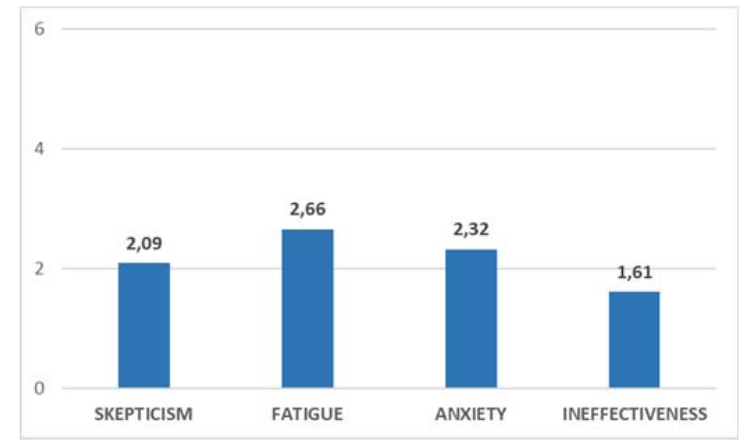

Figure 3. Variables values associated to technostress for the community members (Maximum value =6)

From the results shown in Figure 3., fatigue and anxiety are the two factors that must be controlled the most when using ICTs. Fatigue is characterized by feelings of tiredness and mental and cognitive exhaustion due to the use of technology. Anxiety is characterized by high levels of unpleasant physiological activation and the feeling of tension and discomfort due to the present or future use of some type of ICT. In general, there is no high risk of suffering from technostress in the educational institution since the levels of the 4 variables are below the average value, which is 3 . However, it can be recognized that fatigue and anxiety are the 2 variables that should begin to be controlled to avoid the risk of suffering from technostress in the future. Analysing by age ranges how technostress affects workers, Figure 4. presents the results of the 4 factors considered for participants between 30 and 50 years old.

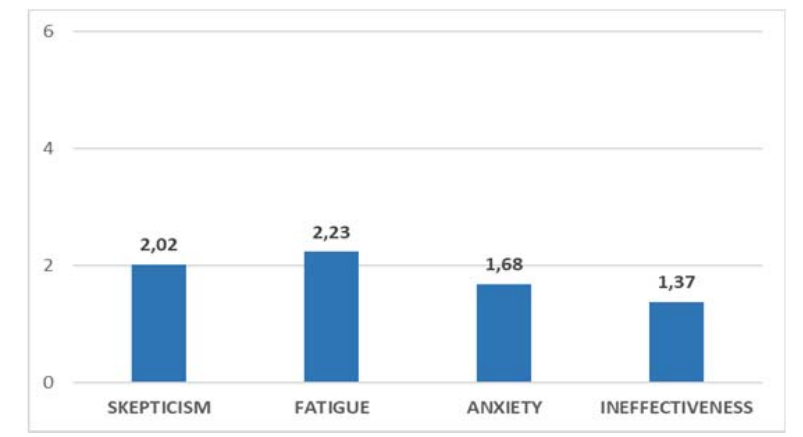

Figure 4. Variables values associated to technostress for the community members between 30 and 50 years of age

From Figure 4., it can be observed among members of the educational community between 30 and 50 years of age that fatigue is the variable that must be controlled the most when using ICTs. As mentioned previously, fatigue is characterized by feelings of tiredness and mental and cognitive exhaustion in terms of using ICTs. Similarly, Figure 5. shows the results of the 4 factors considered (scepticism, fatigue, anxiety, and ineffectiveness) for workers over 50 years of age.

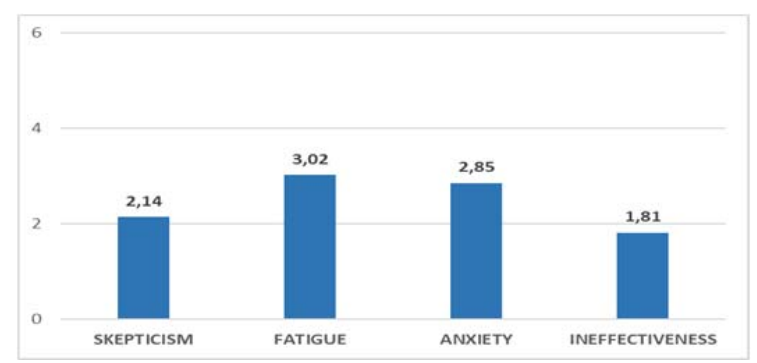

Figure 5. Variables values associated to technostress for the community members over 50 years of age

Figure 5. shows that among members of the educational community over 50 years of age, fatigue and anxiety are the variables that must be controlled the most when using ICTs. Anxiety is characterized by high levels of unpleasant physiological activation and feelings of tension and discomfort due to the present or future use of some type of ICT. It can also be observed how participants over 50 years of age have higher levels of fatigue and anxiety regarding the use of ICTs compared to the ones between 30 and 50 years of age. Thus, this case study allows us to identify that there is a direct relationship between age and the 4 variables or factors associated with technostress (scepticism, fatigue, anxiety, ineffectiveness); the older the person is, the higher the values in the 4 variables. Furthermore, ineffectiveness refers to sceptical attitudes regarding the use of technologies; and at the same time, negative thoughts about one's own capacity and competence with ICTs. On the other hand, when discriminating the analysis by gender, Figure 6 . shows the results obtained for technostress in men while Figure 7. shows the results for women.

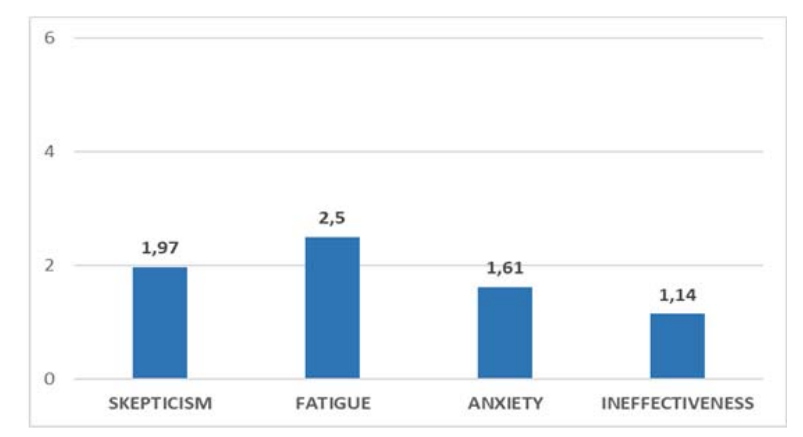

Figure 6. Variables values associated to technostress in men 


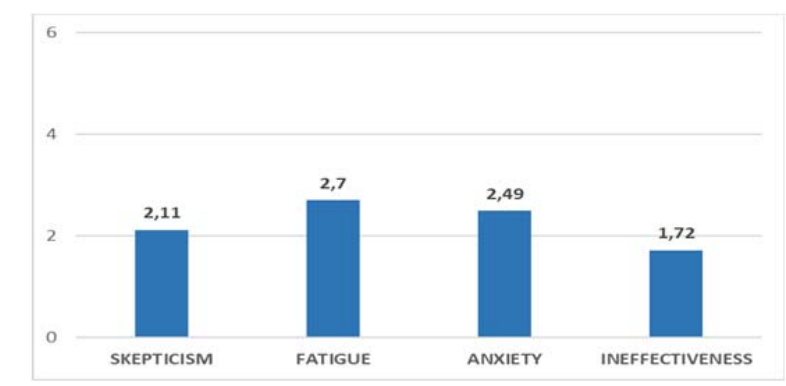

Figure 7. Variables values associated to technostress in women

Comparing the results from Figures 6. and 7., it can be observed that the values of the 4 variables (scepticism, fatigue, anxiety, and ineffectiveness) are always higher in women. Then, for this case study, women are more affected by fatigue and anxiety when using ICTs and men are more affected by fatigue. Similarly, the variable that differs the most between women and men is anxiety. According to the results, men are less anxious than women when using ICTs.

On the other hand, it is important to mention that the Colombian Institute for the Evaluation of Education - ICFES has stipulated the presentation of the Saber tests that evaluate the performance of eleventh grade students according to the basic competencies defined by the Ministry of Education. Because of the pandemic, the test was postponed for 4 months, which is why it was carried out at the end of an atypical 2020 school year that was characterized by working at home. The results obtained from a company dedicated to the management and analysis of data for the evaluations, show how the Institution under study in 2019 in the areas evaluated by the Saber 11 test, obtained a weighted average of 63.769 out of 100 points while in 2020, it obtained a weighted average of 62.154 . These figures show a slight setback in the results of the academic processes from this type of educational organizations. This means they suffer effects on their processes in the face of unexpected events such as a pandemic, and it takes some time to adjust. In this type of educational organizations, it is the teaching and administrative staff who must lead the assimilation of these changes since it is through ICTs that it is possible to carry out the educational process to students when working from home.

\section{Conclusions}

The pandemic caused by COVID-19 has forced educational institutions to adapt their different academic processes, using the advantages provided by ICTs. Despite their advantages, it has been shown that they can have effects on the stress experienced by workers who use them. In this sense, it is vital for the different organizations that have adapted their processes, to carry out diagnoses in their workers in order to mitigate the effects generated by technostress.

This work presents the development of an analysis study for technostress applied to the educational context where the remote presence methodology was adopted. More specifically, a case study was developed on the Nuestra Señora del Carmen Educational Institution in the city of Popayán, a public school that is frequently among the 3 best institutions in the department of Cauca. The case study was aimed at evaluating technostress in teachers, managers, and administrators of the institution.

Therefore, an instrument for the evaluation of technostress was adapted according to what [23] proposed, which assesses the affective, attitudinal, and cognitive dimensions. The adaptation of the instrument, as well as the case study developed, are intended to serve as a reference to be replicated in different organizations in order to evaluate technostress in workers of organizations from different contexts.

The results of the study carried out on teachers, managers, and administrators of the educational institution allowed to conclude that although on the scale from 1 to 6 , the factors of anxiety, fatigue, scepticism, and ineffectiveness do not exceed the value of 3 . Then, it is necessary to pay attention to the factors of anxiety and fatigue, which can promote the future development of technostress in the workers of the educational institution. Likewise, the study made it possible to show how workers over 50 years of age present higher levels of fatigue and anxiety regarding the use of ICTs compared to people between 30 and 50 years of age. Finally, women present higher stress values in the 4 factors studied (anxiety, fatigue, scepticism, and ineffectiveness) compared to men as a result of conducting the study regarding gender. It can also be concluded that while women are more affected by fatigue and anxiety when using ICTs, men are more affected by fatigue only.

Future work is intended to extrapolate this study to organizations of different contexts. In the same way, implementing fuzzy logic for the analysis of the results obtained in the present study is considered relevant. 


\section{References}

[1]. Alemán, I., Vera, E., \& Patino-Torres, M. J. (2020). COVID-19 y la educación médica: retos $\mathrm{y}$ oportunidades en Venezuela. Educación Médica, 21(4), 272-276.

[2]. Cho, M. J., \& Hong, J. P. (2021). The emergence of virtual education during the COVID-19 pandemic: The past, present, and future of the plastic surgery education. Journal of Plastic, Reconstructive \& Aesthetic Surgery, 74(6), 1413-1421.

[3]. Hevia, C., \& Neumeyer, A. (2020). Un marco conceptual para analizar el impacto económico del COVID-19 y sus repercusiones en las políticas. Programa de las Naciones Unidas para el Desarrollo, Buenos Aires-Argentina.

[4]. Almarzooq, Z. I., Lopes, M., \& Kochar, A. (2020). Virtual Learning During the COVID-19 Pandemic: A Disruptive Technology in Graduate Medical Education. J Am Coll Cardiol, 2635-2638. https://doi.org/10.1016/j.jacc.2020.04.015.

[5]. Pal, K. B., Basnet, B. B., Pant, R. R., Bishwakarma, K., Kafle, K., Dhami, N., ... \& Bhatta, Y. R. (2021). Education system of Nepal: impacts and future perspectives of COVID-19 pandemic. Heliyon, e08014.

[6]. García-Peñalvo, F. J., Corell, A., Abella-García, V., \& Grande, M. (2020). Online assessment in higher education in the time of COVID-19. Education in the Knowledge Society, 21.

[7]. Brynjolfsson, E., \& Hitt, L. M. (2000). Beyond computation: Information technology, organizational transformation and business performance. Journal of Economic perspectives, 14(4), 23-48.

[8]. La Torre, G., Esposito, A., Sciarra, I., \& Chiappetta, M. (2019). Definition, symptoms and risk of technostress: a systematic review. International archives of occupational and environmental health, 92(1), 13-35.

[9]. Tarafdar, M., Tu, Q., Ragu-Nathan, B. S., \& RaguNathan, T. S. (2007). The impact of technostress on role stress and productivity. Journal of management information systems, 24(1), 301-328.

[10]. Velázquez, A. G., \& de León Jiménez, S. (2010). Ambientes colaborativos vs entrés laboral en la era de la información. Revista Gestión y estrategia, (37), 4960.

[11]. Soria, M. S. (2003). Trabajando con tecnologías y afrontando el tecnoestrés: el rol de las creencias de eficacia. Revista de Psicología del Trabajo y de las Organizaciones, 19(3), 225-246.
[12]. Cuervo Carabel, T., Orviz Martínez, N., Arce García, S., \& Fernández Suárez, I. (2018). Tecnoestrés en la Sociedad de la Tecnología y la Comunicación: Revisión bibliográfica a partir de la Web of Science. Archivos de Prevención de Riesgos Laborales, 21(1), 18-25.

[13]. Díaz-Álvarez, E. (2020). Tecnoestress. Revista Ocronos, 3(5).

[14]. Salazar-Concha, C., Ficapal-Cusí, P., \& Boada-Grau, J. (2020). Tecnoestrés. Evolución del concepto y sus principales consecuencias. TEUKEN BIDIKAY. Revista Latinoamericana de Investigación en Organizaciones, Ambiente y Sociedad., 11(17), 165180.

[15]. Lozano, G. M. (2008). Tecnoestrés: identificación, valoración y control (II). Gestión práctica de riesgos laborales: Integración y desarrollo de la gestión de la prevención, (48), 20-27.

[16]. Brooks, S., \& Califf, C. (2017). Social mediainduced technostress: Its impact on the job performance of it professionals and the moderating role of job characteristics. Computer networks, 114, 143-153.

[17]. Kim, H. J., Lee, C. C., Yun, H., \& Im, K. S. (2015). An examination of work exhaustion in the mobile enterprise environment. Technological forecasting and social change, 100, 255-266.

[18]. Chanchí, G. E., Ospina, M. A., \& Ospino, M. E. (2020). Análisis de sentimientos de la percepción de los estudiantes de Ingeniería de Sistemas de la Universidad de Cartagena (Colombia) sobre las actividades académicas desarrolladas durante el confinamiento debido al COVID-19. Espacios, 41(42), 247-259.

[19]. Misuraca, R., \& Ceresia, F. (2020). Psychological Reactance as an explanation of Italians' resistance to observe the safety measures during COVID-19 outbreak. Revista de Ciencias Sociales (Ve), 26(4), $15-22$.

[20]. Viejo, J. M. P., Barbé, A. D., Pérez, M. D. M. R. B., \& Pérez, J. L. (2020). Resiliencia para la promoción de la salud en la crisis Covid-19 en España. Revista de ciencias sociales, 26(4), 52-63.

[21]. Chacín, A. J. P., González, A. I., \& Peñaloza, D. W. (2020). Educación superior e investigación en Latinoamérica: Transición al uso de tecnologías digitales por Covid-19. Revista de Ciencias Sociales, 26(3), 98-117.

[22]. Expósito, E., \& Marsollier, R. (2020). Virtualidad y educación en tiempos de COVID-19. Un estudio empírico en Argentina. Educación y Humanismo, 22 (39), 1-22.

[23]. Salanova, M., Llorens, S., Cifre, E., \& Nogareda, C. (2004). Tecnoestrés: concepto, medida e intervención psicosocial. Nota técnica de prevención. 